\title{
Who allowed the speaker to use my patient's photo?
}

\author{
P Snyman \\ Department of Paediatrics, University of Pretoria \\ P Snyman, FCPaed, MB ChB, Dip PEC, DCH
}

Corresponding author: P Snyman (philip.snyman@up.ac.za)

Clinical photography is used in publications, teaching, lecture illustration and research. Nowadays virtually every medical doctor and medical student possesses a camera phone. The patient or the parent is often not asked for consent, or even aware that pictures have been taken with these devices. Medical colleagues may obtain photos we have taken, and use them without our consent. These new developments in digital media technology require a re-think of many ethical positions and legal implications.

S Afr J CH 2012;6(4):102-105. DOI:10.7196/SAJCH.457

'Patients are people - people with problems. They are often in pain and usually apprehensive. To them, the medical photographer is someone who, once more, submits them to an institutional routine. He takes their pictures, with part or all of their clothing removed, to show what is usually an embarrassing condition or deformity. Again, indispensable as photography is in the teaching and advancing of medicine, it does not present to the patient the same direct benefit as a radiograph or a blood test.'

Clinical photography is a well-established tool and discipline, used in publications, teaching, lecture illustration and research. Nowadays virtually every doctor and medical student possesses a smart phone or cell phone with a fairly good-quality camera attached to it. Such a device is unobtrusive and conveniently pocketable. The patient or the parent is often not asked for consent, and may not even be aware that pictures were taken. Medical colleagues may obtain photos by copying a presentation, or by way of Bluetooth transfers and other means.

Recently a baby with multiple deformities was brought to our hospital. After obtaining verbal parental consent, the patient was photographed with a smart phone. The pictures were forwarded to a colleague, who was able to make a diagnosis on the basis of the photographs.

It was subsequently discovered that the colleague had used these photographs in a lecture at an international conference, without either the mother's or the photographer's consent or acknowledgement.

New developments in digital media technology require a re-think of many ethical positions and legal implications. The above case prompted the following questions:

- Is it ethically acceptable to use pictures taken by somebody else without requesting permission or acknowledgement?

- Should the mother have been asked for consent to use the photo in a lecture?

In another case, an avid clinical photographer had over many years taken photographs of patients with pronounced untreated pathology and of clinical rarities. When he retired and left the whole databank of priceless clinical photographs to his colleagues, they found that they could not publish them because there were no consent forms. In addition, the university claimed copyright because the photographs had been taken by a university employee. Here the legal issues to consider include:

- Who has ownership of or holds the copyright to clinical photographs? - May old photographs be published if patient consent is unavailable?

\section{Discussion}

While many of the issues may appear to be straightforward (Table 1), others are complex and open to differing interpretations.

\section{Legal aspects}

According to the law as it relates to photographers in South Africa, there are only three areas that a photographer is likely to be confronted with, namely copyright, privacy and trespass laws..$^{2,3,16}$

While it is a photographer's right to take pictures in public places in South Africa, and nobody can be prevented from taking photos or from deleting them from the camera, ${ }^{3,17}$ it should be kept in mind that a hospital cannot be seen as a public place, so the abovementioned rule does not apply. However, the taking and publishing of photos are two different matters altogether.

Legal documents of importance in the South African setting, namely the Children's Act 38 of 2005, the National Health Act of 2003, the Protection of Personal Information Bill of 2009 and the Health Professions Council of South Africa (HPCSA) Guidelines, relate to data-keeping but are vague about medical photography as such. Principles emanating from these documents are:

- The best interests of the child are paramount. ${ }^{18}$

- Safe record keeping ${ }^{2,19}$ is very important, confidentiality should be upheld, and access to information should be restricted (one may not falsify or change records). ${ }^{19}$

- Personal information is private and consent should be obtained to acquire and use it; safekeeping is mandatory. ${ }^{16}$

\section{Ownership}

The photographer is always the owner of the photographs..$^{14,20}$ No one may use someone else's pictures without having obtained permission. Sharing photos with colleagues poses many problems, of which loss of control of their use is only one. The fact and manner of acquisition or possession do not transfer the right of further use. 
Table 1. Legal and ethical issues in clinical photography ${ }^{2-15}$

\begin{tabular}{ll}
\hline Legal issues & Ethical issues \\
\hline Ownership & Right to privacy/confidentiality/anonymity \\
Legally binding consent & Autonomy - consent \\
Permissible editing of pictures & Non-maleficence \\
Storage/safe record keeping & Beneficence \\
Backups and copying & Fidelity \\
Photo editing & Justice \\
Theft & Right to refuse \\
Child abuse & Dignity \\
Photographer's right & Professionalism \\
Institution's policy documents &
\end{tabular}

The best thing is to have a good working relationship with a photosharing colleague and a mutual understanding of consent issues and ownership of pictures.

Anyone using someone else's pictures in a public way should acknowledge and credit the photographer. To be ethically correct, colleagues should eventually also delete pictures sent to them for evaluation/consultation purposes, or obtain the relevant permission from the rightful owner.

It is likely that copyright issues will become increasingly important in future, and the various parties concerned will have to debate and decide these beforehand.

\section{Informed consent}

Is it good enough just to get verbal consent for taking pictures? In the past this may have been sufficient if the photograph was to be used only for educational purposes or, as in the case above, for consultation. Nowadays, however, ethical guidelines preclude this, and written consent is regarded as a requirement. ${ }^{21} \mathrm{It}$ is far better to be pro-active. In obtaining consent, the form should specify whether the photographs are to be used for purposes other than teaching alone, such as publication. ${ }^{7,14,22}$ Most medical journals require written consent forms when pictures are involved. While the patient's file is acceptable for storage of the consent form, in practice it would be better to keep a record of such a consent form with the photo (it may even be a photocopy).

Can a minor give consent for having his/her picture taken, and when might such consent from a minor be legally binding? No clear guidelines exist in South Africa, but recommended current practice is to obtain assent from children as young as 7 years of age. ${ }^{21}$

It may also be necessary to obtain consent for the secondary use of pictures by someone else, such as a colleague. One must keep in mind that patients can withdraw their consent at any time, and the doctor will then have to delete all copies in his/her possession - fortunately this hardly ever happens.

In South Africa the HPCSA guidelines bind doctors to keep patients' records safe for a minimum of 6 years. This implies photos as well. However, when these records relate to children, they should be kept until the patient's 25 th birthday ('thus allowing 3 to 4 years after reaching majority to enable the individual to submit a claim, should there exist any grounds for such a plan'). ${ }^{2}$

Furthermore, the rules state that 'Records shall be stored in a safe place and if they are in electronic format, safeguarded by passwords. Practitioners should satisfy themselves that they are informed of the
Board's guidelines with regard to the retention of patient records on computer compact discs.'

Even when consent has been obtained, the following principles apply to the use of photographs for publication or presentation:

- Pictures should be shown to the patient.

- The patient's anonymity should be protected.

- Children aged from $7-8$ years should consent to their picture being taken.

- Consent may be withdrawn at any time.

- Even with anonymous pictures, such as histological stains or $\mathrm{X}$-rays, consent for publication is needed.

- In cases of child abuse, the signature of the hospital CEO, the doctor and preferably a parent should be obtained.

\section{Ethical considerations}

In South Africa no functional ethical guidelines exist for the practice of telemedicine, ${ }^{24,25}$ and it is not yet standard practice for teaching hospitals and institutions to have a written policy regarding the use of mobile and camera phones, cameras and video recording devices. Elsewhere, such institutional documents are being introduced as a matter of policy. ${ }^{26}$ The patient's rights and concerns should be at the forefront of any such policy, and any document emanating from it should be easily accessible to staff, patients and visitors. All staff should be aware of the policy and the reasons for it, and it should be reviewed periodically.

A large number of ethical issues can crop up in clinical photography. The right to privacy and patient autonomy are paramount in medical photography, but other principles should also be considered, as follows:

\section{The right to privacy/confidentiality/anonymity}

'The right to privacy is our right to keep a domain around us (such as our body or identity). It gives us the ability to choose which parts in this domain can be accessed by others, and to control the extent, manner and timing of the use of those parts we choose to disclose. ${ }^{27}$ Accordingly, the patient's identity should not be revealed (e.g. by hospital numbers, X-rays or results), and facial features should be disguised as far as possible (covering the eyes may not be enough, because other features might identify the patient). One exception may be in sexual assault cases or where facial pathology needs to be visualised. The patient's anonymity should be protected at all costs.

The privacy principle may be violated by being unnecessarily intrusive. There is often no need to show the whole body (or the genitals!). Patients and their parents may require explanation of the limits of confidentiality in a teaching or consultation context. 


\section{Patient autonomy}

Respect for patient autonomy requires that the following aspects be considered. Has informed written consent been obtained? Were all copies discarded after the patient withdrew consent? Was the person's right to decline his/her consent to photography respected? Notwithstanding consent from the parent/guardian/caregiver, was the child given an opportunity to actively agree to participate and was refusal to participate respected and honoured? ${ }^{16}$

\section{Non-maleficence, beneficence, fidelity, justice}

These ethical principles help the photographer to consider whether he/she is perhaps doing harm to the patient, how the photograph will actually help the patient, whether the photographs are being used in a context that represents the real situation and identity, and whether patients are being photographed with the same respect as they would be in their home community.

\section{Dignity}

Nudity or showing the genitalia would be regarded as an infringement of the patient's right to dignity and confidentiality. Anonymity should be guaranteed and facial features should be disguised where possible.

\section{Professionalism and respect for the patient}

The photography session should not be tiring for the patient.

\section{Photo editing}

Pictures may be edited digitally to enhance colours and effects. Editorial photography is intended for objective and accurate representation of a real situation and subject. Editing should never distort the true context, content or meaning of a photograph.

Allowable adjustments and alterations include brightness, contrast, colour balance, sharpening and saturation, cropping and fixing red-eyes. ${ }^{28}$

Non-permissible alterations include removing, cloning, combining or adding something, changing colour or stretching or compressing a part of the image..$^{29}$

Fig. 1 ( $\mathrm{a}$ and $\mathrm{b}$ ) illustrates how digital editing can change the appearance of photographs.

Actions that constitute misuse:

- Using a photo to illustrate a patient condition when there is no evidence to support a connection.

- Using a photo out of context.

- Using a photo to portray someone from another country.

- Making a false/unfair statement, e.g. a photo of a mother breastfeeding to depict 'mother-to-child transmission of HIV'. Appropriate disclosures should be included to prevent
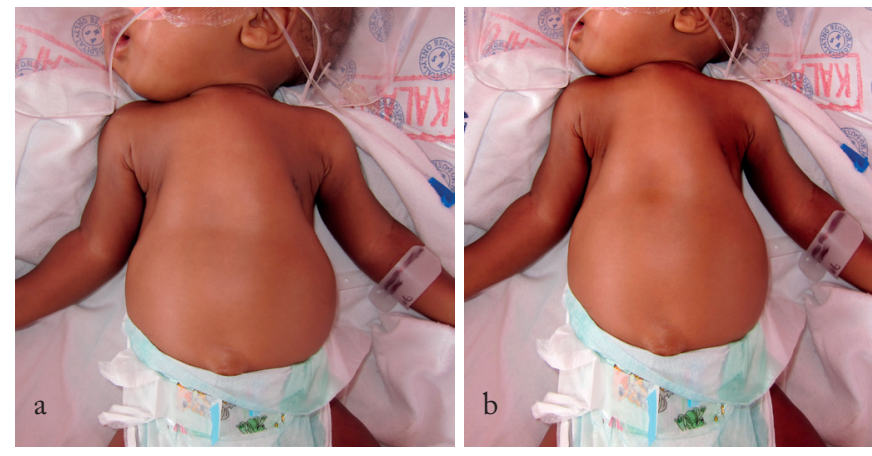

Fig. 1. How digital editing can change the appearance of photographs. The original version (cropped only) is show in a. In b, the perspective has been changed and the picture cropped, shadows have been inserted, and small colour and contrast changes have been added. misunderstandings, e.g. 'The photo is used for illustrative purposes only. It does not imply that this person has HIV.'

\section{Implications for doctors}

Medical photography is a wonderful teaching tool in medical practice and it has evolved considerably over the last decade, with new technologies coming into daily practice. It has broadened the scope of possibilities immensely for practitioners with regard to teaching, learning and consultation. Table 2 lists the legal and ethical requirements of clinical photography.

\section{Table 2. Clinical photography implications for doctors}

Get informed consent - use a consent form and keep a photocopy ready Store pictures safely - until 25th birthday for children (HPCSA)

Make backups

Be aware of picture-sharing pitfalls and copyright issues

Be aware of legal implications - safekeeping

The photographer is the owner of the photos

Give credit to other authors when using their pictures

Edit pictures with discretion

Discard others' pictures

\section{Medical Photography Name: Consent Form 屝 $\begin{aligned} & \text { Hospital number: } \\ & \text { Ward: }\end{aligned}$ Patient Consent: I, (relationship to patient) hereby consent to medica images and / or video being made of me / my child / my dependent / the patient.
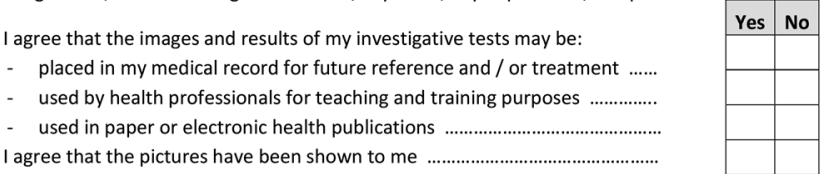

By signing below, I confirm that I understand this consent form. No royalty fees will be paid. Signature of Patient (or fingerprint):

Signature of Parent / Guardian / CEO (of Hospital):

Date:

Signature of Doctor / Health Professional:

Date:

Please indicate wit

rectangular drawings on this picture, which areas were photographed:

Patient's name and hospital number will not be revealed or published. Anonymity will be pursued and facial features will be disguised where possible.

Material will not be used for advertising.

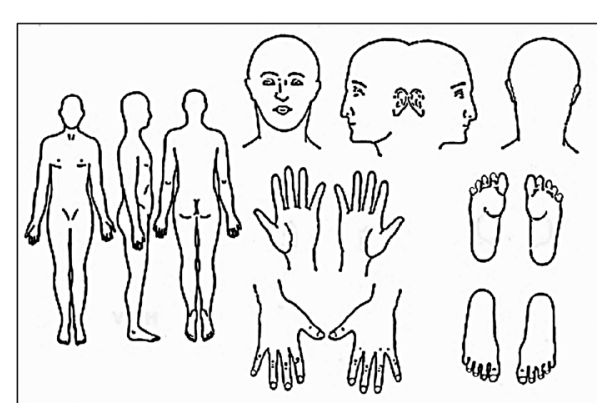

Fig. 2. Consent form (photo by Oystein Horgmo, ${ }^{30}$ Photography Section, University of Oslo). 
Fig. 2 is an example of a consent form that was compiled from various web-based documents. ${ }^{7,14,30-32}$ photography have opened a host of legal and ethical implications for doctors, their institutions and their patients. With the real possibility of misuse of patient photos and the potential legal consequences arising therefrom, the case is made for medical institutions to adopt written policy statements regarding the use of mobile and camera phones, cameras and video recording devices. ${ }^{26}$

Acknowledgement. Professor D F Wittenberg is thanked for invaluable support and helpful suggestions.

\section{Conclusion}

The technological possibilities of digital

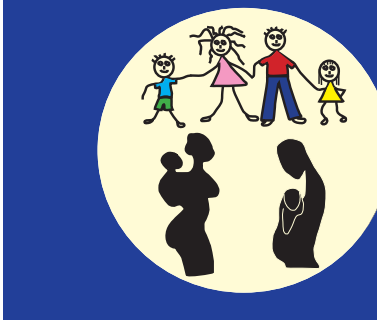

Editing should never

distort the true context, content or meaning of a photograph.
14. Segal J, Sacopulos MJ. Photography consent and related legal issues. Facial Plast Surg Clin North Am 2010;18:237-244. [http://dx.doi.org/10.1016/j. fsc.2010.01.003]

15. Brennan PAW. The medical and ethical aspects of photography in the sexual assault examination: Why does it offend? Journal of Clinical Forensic Medicine 2006;13:194-206. [http://dx.doi.org/10.1016/j. jcfm.2006.02.004]

16. Protection of Personal Information Bill (B9 2009). Document No. 207372. Government Gazette No. 32495 of 14 August 2009. http:// www.parliament.gov.za/live/content.php?Item $\mathrm{ID}=216 \&$ DocumentNumber $=207372$ (accessed 30 October 2012).

17. Cheesman C. Police pay photographer thousands in deleted images row. Amateur Photographer. 2011 (February). http://www.amateurphotographer. co.uk/news/police_pay_photographer_thousands in_deleted_images_row_news_305659.html?aff=rss (accessed 20 December 2011).

\section{References}

1. Gibson HL. Medical photography; clinical-ultraviolet-infrared. 1973. http:// sterileeye.com/2009/10/06/the-patient-and-the-photographer/ (accessed 26 March 2012).

2. Health Professions Council of South Africa. Medical and Dental Professions Board. Guidelines on Keeping of Patient Records. Guidelines for Good Practice in Medicine, Dentistry and the Medical Sciences, Booklet 11. Pretoria: HPCSA, October 2002.

3. Onderstall J. The law as it pertains to photographers in South Africa. PIX. 2011. http://pixmag.ning.com/forum/topics/the-law-as-it-pertains-to?page= 18commentId $=2377935 \% 3$ AComment $\% 3$ A562030\&x $=1 \# 2377935$ Comme nt562030 (accessed 20 December 2011).

4. Creighton S, Anderson J, Brown S, et al. Medical photography: ethics, consent and the intersex patient. BJU International 2002;89:67-72. [http://dx.doi. $\operatorname{org} / 10.1046 / \mathrm{j} .1464-4096.2001 .01809 . x]$

5. Hood CA, Hope T, Dove P. Videos, photographs, and patient consent. BMJ 1998;316:1009. [http://dx.doi.org/10.1136/bmj.316.7136.1009]

6. Taylor D McG, Foster E, Dunkin CSJ, Fitzgerald AM. A study of the personal use of digital photography within plastic surgery. J Plast Reconstr Aesthet Surg 2008;61:37-40.

7. Windsor JS, Rodway GW, Middleton PM, McCarthy S. Digital photography. Postgrad Med J 2006;82:688-692. [http://dx.doi.org/10.1136/ pgmj.2006.044990]

8. Berle I. Clinical photography and patient rights: the need for orthopraxy.J Med Ethics 2008;34:89-92. [http://dx.doi.org/10.1136/jme.2006.019166]

9. Lau CK, Schumacher HHA, Irwin MS. Patients' perception of medical photography. J Plast Reconstr Aesthet Surg 2010;63:e507-e511. [http:// dx.doi.org/10.1016/j.bjps.2009.11.005]

10. General Medical Council (England). Making and using visual and audio recordings of patients. Supplementary guidance. April 2011|1. http://www. gmc-uk.org/static/documents/content/Making_and_using_visual_and_ audio_recordings_of_patients_2011.pdf (accessed 21 December 2011).

11. Whiddett R, Hunter I, Engelbrecht J, Handy J. Patients' attitudes towards sharing their health information. International Journal of Medical Informatics. 2006;75:530-541. [http://dx.doi.org/10.1016/j.ijmedinf.2005.08.009]

12. Hill K. Consent, confidentiality and record keeping for the recording and usage of medical images. J Vis Commun Med 2006;29(2):76-79. [http://dx.doi. org/10.1080/01405110600863365]

13. Bhangoo P, Maconochie IK, Batrick N, Henry E. Clinicians taking pictures - a survey of current practice in emergency departments and proposed recommendations of best practice. Emerg Med J 2005;22:761-765. [http:// dx.doi.org/10.1136/emj.2004.016972]
18. Children's Act 38 of 2005. Government Gazette No. 28944. Pretoria: Government Printer, 2006.

19. National Health Act 61 of 2003. Government Gazette No. 26595. Pretoria: Government Printer, 2004.

20. Pitman AG, Hare WSC. Letter: Re: Ownership of medical images. Australasian Radiology 2007;51:201-202. [http://dx.doi.org/10.1111/j.14401673.2007.01709.x]

21. Vanderbilt University Medical Center. Patient photography and video imaging. 2010. http://www.mc.vanderbilt.edu/documents/The\%20Learning\%20Center/ files/Photo\%20Policy.pdf (accessed 18 September 2012).

22. Groves T, Croot J. Using pictures in the BMJ. BMJ 2005;330:916. [http:// dx.doi.org/10.1136/bmj.330.7497.916] (accessed 30 October 2012).

23. Tranberg HA, Rous BA, Rashbass J. Legal and ethical issues in the use of anonymous images in pathology teaching and research. Histopathology 2003;42:104-109. [http://dx.doi.org/10.1046/j.1365-2559.2003.01575.x]

24. Jack C, Mars M. Telemedicine a need for ethical and legal guidelines in South Africa. South African Family Practice 2008;50(2):60.

25. Mars M, Jack C. Why is telemedicine a challenge to the regulators? South African Journal of Bioethics and Law 2010;3(2):55-58.

26. Using mobile phones in NHS hospitals (Department of Health, 2009). http://www.dh.gov.uk/prod_consum_dh/groups/dh_digitalassets/@dh/@en/ documents/digitalasset/dh_092812.pdf (accessed 20 December 2011).

27. Onn Y, Geva M, Druckman Y, et al. Privacy in the digital environment, Haifa Center of Law \& Technology. 2005;7:1-12. http://weblaw.haifa.ac.il/ he/Research/ResearchCenters/techlaw/DocLib/Privacy_eng.pdf (accessed 29 October 2012)

28. Mastroianni E. Fine art photography vs. documentary photojournalism. The line on digital alteration. http://www.naturescapes.net/docs/index.php/ conservation-and-ethics/40-conservation-a-ethics/345-fine-art-photographyvs-documentary-photojournalism- (accessed 22 December 2011).

29. Reza Nouraei SA, Frame J, Nduka C. Uses and abuses of digital imaging in plastic surgery. Int J Surg 2005;3:254-257. [http://dx.doi.org/10.1016/j. ijsu.2005.10.004]

30. Horgmo O. Picture card. http://sterileeye.com/2010/05/18/the-card/ (accessed 20 December 2011).

31. Aglow Dermatology. Medical photography consent form. http://www. dinastrachanmd.com/wp-content/uploads/2011/05/medical-photographyconsent-form.pdf (accessed 22 December 2011).

32. Dysmorphology Subcommittee of the Clinical Practice Committee, American College of Medical Genetics. ACMG Statement. Informed consent for medical photographs. Genet Med 2000;2(6):353-355. 